\title{
Influence of spreading structure in an aqueous solution-hydrocarbon system on extinguishing of the flame of oil products
}

\author{
Dmitriy Korolchenko ${ }^{1 *}$ and Sergey Voevoda ${ }^{2}$ \\ ${ }^{1}$ Moscow State University of Civil Engineering, 129337, Moscow, Yaroslavskoye sh., 26, Russia \\ ${ }^{2}$ Transneft Research Institute for Oil and Oil Products Transportation (Transneft R\&D, LLC),117186, \\ Moscow, Sevastopolskiy prospect, 47A, Russia
}

\begin{abstract}
On the basis of experimental studies it was revealed that adding of electrolyte - ammonium chloride - into solution of film-forming foaming agent leads to decrease of interfacial tension on a border with heptane, and increase of surface tension on a border with air. It is experimentally shown that dependence between specific consumption and flow rate of foaming agent passes through the minimum point that allowed defining influence of electrolyte on a value of minimum specific consumption and optimum flow rate of foam during extinguishing of a hydrocarbon flame. The structure of spreading in a foaming agent solution - hydrocarbon system defines the value of fire extin-guishing efficiency of foam decreasing together with lowering of spreading coefficient and interfacial tension.
\end{abstract}

\section{Introduction}

The structure of spreading in a solution-hydrocarbon system mainly defines fire extinguishing efficiency of foam during extinguishing of the flame of oil products [1-4]. Spreading in a solution - hydrocarbon system has a complex structure which is firstly divided by sign and value of spreading coefficient of aqueous solution, flowing over hydrocarbon, and hydrocarbon, flowing over aqueous solution. The structure of spreading coefficient consists of values of surface and interfacial tensions. For calculation of spreading coefficient of aqueous solution - K10 and heptane - K 01 we use the known ratios:

$$
\begin{gathered}
K_{10}=\sigma_{0}-\left(\sigma_{10}+\sigma_{1}\right) \\
K_{01}=\sigma_{1}-\left(\sigma_{10}+\sigma_{0}\right)
\end{gathered}
$$

where - surface tension of heptane, $\mathrm{mN} / \mathrm{m}$; - interfacial surface tension on a solutionheptane bor-der, $\mathrm{mN} / \mathrm{m}$; - surface tension of aqueous solution on a border with air, $\mathrm{mN} / \mathrm{m}$.

The positive sign of spreading coefficient of aqueous solution is provided due to application of fluorinated SAS (surface-active substances), whereas spreading coefficient of heptane could have the positive sign in case of application of hydrocarbon SAS. Using of combined compounds, containing hydrocarbon SAS as the main component and fluorinated SAS as the small additives, leads to various situations in mutual spreading and wetting in a solution - hydrocarbon system. Role of interfacial tension in the structure of spreading coefficient can be revealed under conditions when spreading coefficient has positive value

${ }^{*}$ Corresponding author: da-vip@mail.ru 
and interfacial tension changes from $2,5 \mathrm{mN} / \mathrm{m}$ to $0,2 \mathrm{mN} / \mathrm{m}$. It is known that electrolytes reduce interfacial tension of aqueous solutions of surfactants that sharply increases surface tension of aqueous solution on a border with air. For effective extinguishing of emergency spill of oil product by compact streams of foam given into the bottom of tank or into the fire zone from long distance, it is necessary to provide positive value of spreading coefficient of solution [5-8]. In the course of experiments it has been revealed that decrease of interfacial tension concurrently increases specific consumption of foaming agent.

The aim of this research is to identify the role of interfacial tension value in ensuring of optimum parameters dur-ing extinguishing of the flame of oil products. For this purpose it have been conducted experimental studies during which value of spreading coefficient was supported on a positive level, while value of interfacial tension was gradu-ally reduced due to additives of electrolyte - ammonium chloride. The difficulty of experiment was in searching of stabilizers which could provide constancy of surface tension of aqueous solutions at a high concentration of salt. It became possible to lower the interphase tension from $2,2 \mathrm{mN} / \mathrm{m}$ to $0,1 \mathrm{mN} / \mathrm{m}$. As a rule, positive value of spreading coefficient of aqueous solution causes high fire extinguishing efficiency of foam giving onto the burning surface and into the bottom of tank, directly into the layer of fuel [9-16].

Under the terms of research, foaming agent should contain fluorinated stabilizers which provide value of surface tension less than $20 \mathrm{mN} / \mathrm{m}$. As the basis it was used mixture of primary alkylsulfates, with carbon chain of $8-12$ atoms, and $0,05 \mathrm{~m} \%$ (mass percent) of perfluorochemical sulfobetaine with radical, containing eight perfluorochemical atoms of carbon. Production of this component is limited in connection with its negative influ-ence on environment. Results of extinguishing of a heptane flame by giving of foam into the bottom of tank are presented in fig. 1. As the concentration of electrolyte - ammonium chloride - increases, the spreading coefficient of solution remains con-stant after slight decrease. The value of spreading coefficient of fuel, flowing over solution, increases. Interfacial tension sharply decreases from $2,0 \mathrm{mN} / \mathrm{m}$ to $0,1 \mathrm{mN} / \mathrm{m}$. Curves of dependence of specific consumption on flow rate of foam solution are presented in fig. 2.

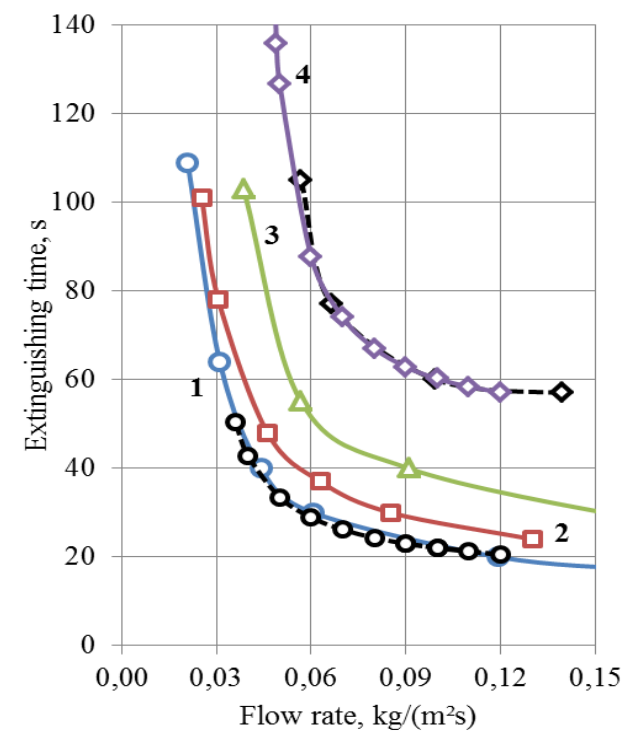

Fig.1. Dependence of extinguishing time on flow rate of foam at a various content of ammonium chloride in aqueous solution, $\mathrm{m} \%: 1-0,0 ; 2-2,0 ; 3-5,0 ; 4-10,0 ; 5-20,0$. (Curves, calculated by 
formula (1), are shown by dotted line).

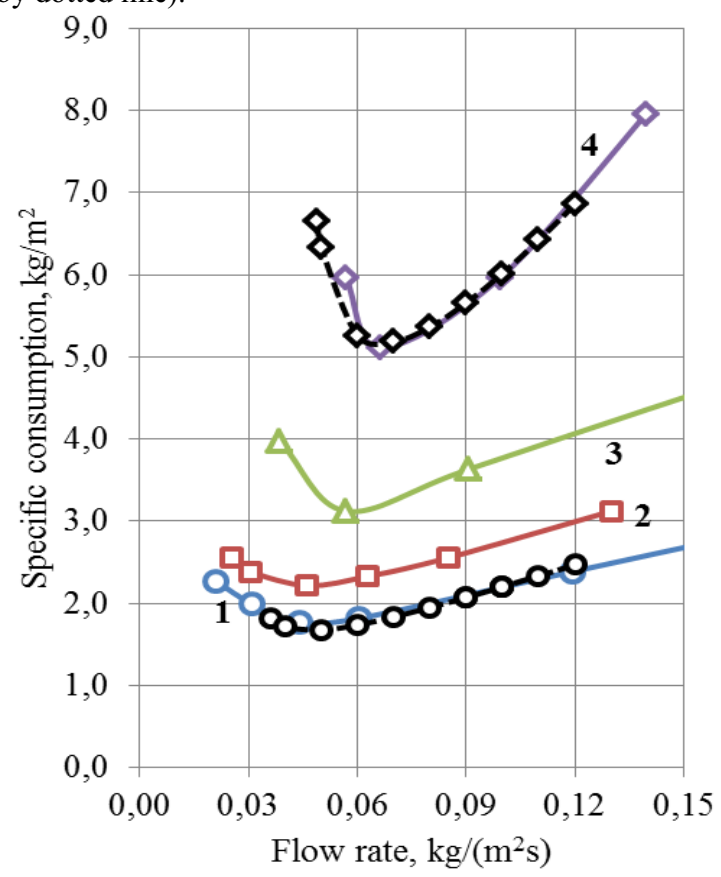

Fig.2. Dependence of specific consumption on flow rate of foam at a various content of ammonium chloride in aqueous solution, $\mathrm{m} \%: 1-0,0 ; 2-2,0 ; 3-5,0 ; 4-10,0$. (Curves, calculated by formula (2), are shown by dotted line).

Curves of dependence have the obviously expressed minimum point which is displaced to the area of large values in process of increase of electrolyte concentration and decrease of interfacial tension. Decrease of interfacial tension leads to increase of minimum consumption of foaming agent and optimum flow rate of foam. Extinguishing time increases synchronously.

Dependence of surface and interfacial tensions on concentration of foaming agent, at constant content of ammonium chloride, is presented in fig. 3. Increase of surface tension and decrease of interfacial tension can be related to influence of electrolyte additives on dissociation degree of molecules of a surface-active basis of foaming agent. Molecules of amphoteric SAS lose dissociation ability and behave as nonionic SAS at high concentration of electrolyte. 


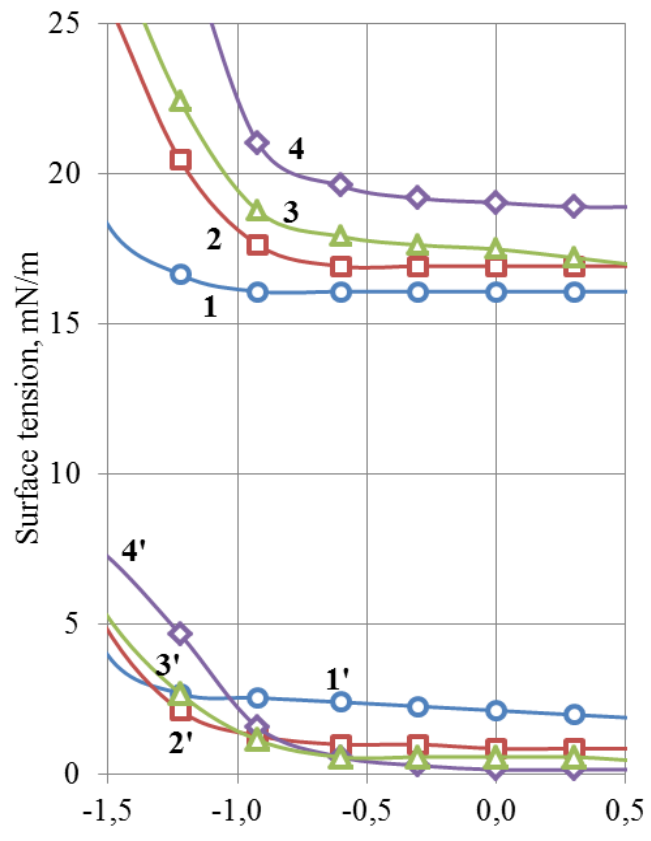

Logarithm of concentration, $\mathrm{m} \%$.

Fig. 3. Isothermal curves of surface (1-4) and interfacial $\left(1^{\prime}-4^{\prime}\right)$ tensions of aqueous solutions on a border with air and heptane at a content of ammonium chloride, $\mathrm{m} \%: 1,1^{\prime}-0,0 ; 2,2^{\prime}-2,0 ; 3,3^{\prime}-5,0 ; 4$, $4^{\prime}-10,0$.

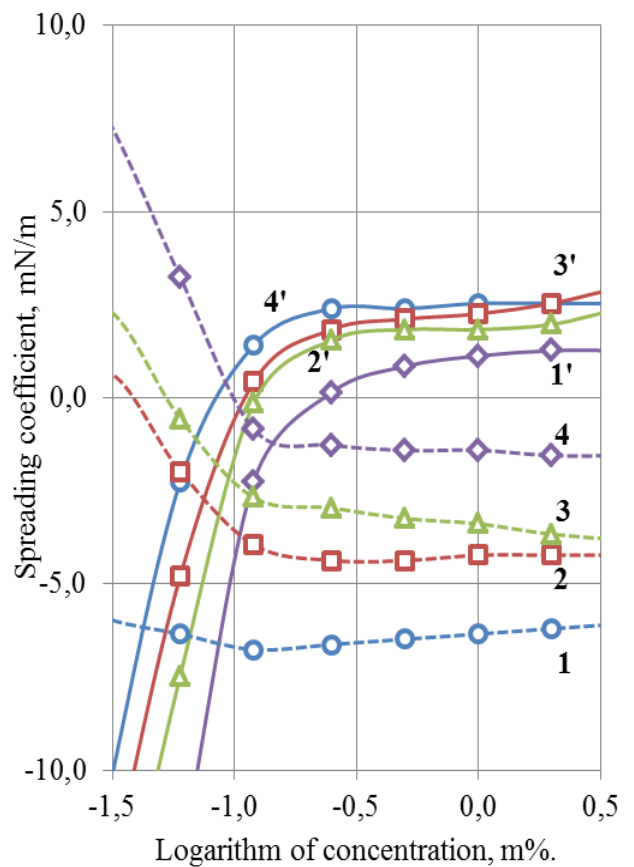

Fig. 4. Influence of ammonium chloride on spreading coefficient of solution flowing over heptane and heptane flowing over foam solution at a content of ammonium chloride, $\mathrm{m} \%: 1,1 *_{-} 0,0 ; 2,2 *_{-}$ 
2,$0 ; 3,3 *-5,0 ; 4,4 *-10,0 ; 5,5 *-20,0$.

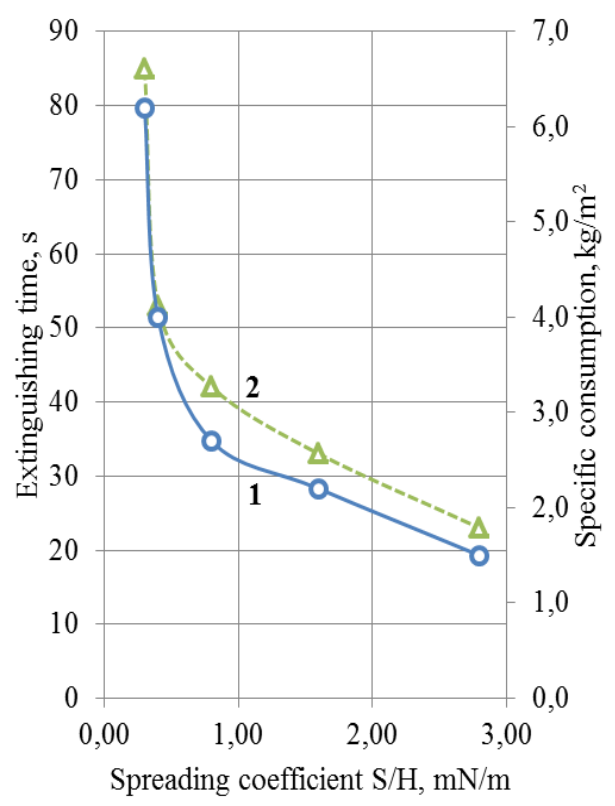

Fig.5. Dependence of heptane extinguishing time (1) and specific consumption of fluorinated SAS solution with electrolyte $\mathrm{NH}_{4} \mathrm{Cl}(2)$ on spreading coefficient of solution, flowing over heptane $(\mathrm{S} / \mathrm{H})$.

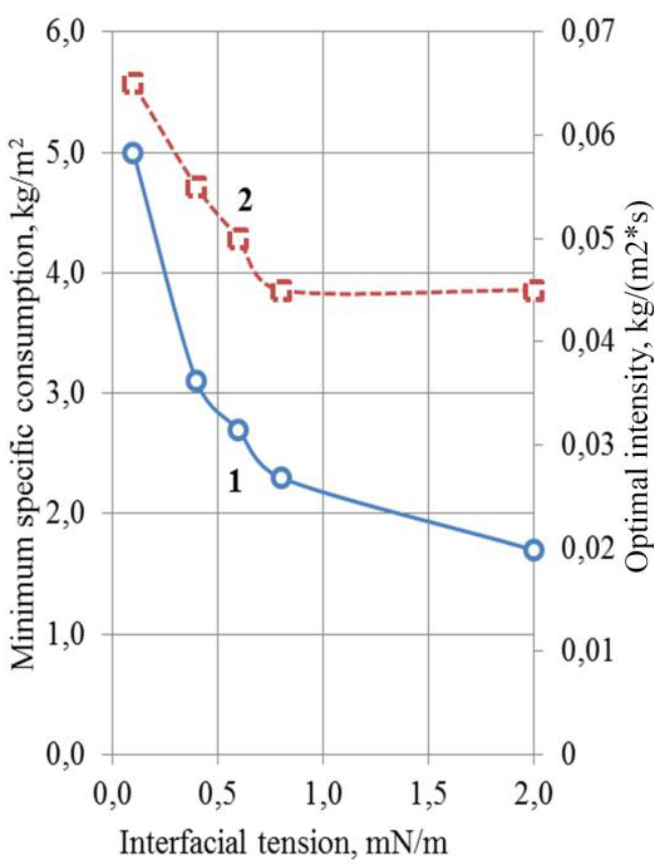

Fig.6. Dependence of minimum specific consumption (1) and optimum flow rate of foam on interfacial tension during extinguishing of a heptane flame by foam solution with ammonium chloride additives. 
Dependence, presented in fig. 4, illustrates changes of two spreading parameters concurrently. The spreading coefficient of solution, flowing over heptane, slightly decreases, but keeps positive value. While the spreading coef-ficient of a heptane, flowing over solution, gradually increases from $-6,0 \mathrm{mN} / \mathrm{m}$ to $-1,5 \mathrm{mN} / \mathrm{m}$. Increase of concentration of a salt leads to decrease of interfacial tension on a border with heptane, and, as a result, fire extinguishing efficiency also decreases. This fact is more important as in this case value of spreading coefficient of solution re-mains positive, i.e. aqueous solution keeps the possibility of spontaneous spreading over hydrocarbon. Dependen-cies of spreading coefficient and value of interfacial tension are presented in fig. 5 and fig. 6. Fire extinguishing ef-ficiency of foam becomes lower together with declining of hydrocarbon spreading over solution and decreasing of interfacial tension.

It is important conclusion that decrease of interfacial tension, if spreading coefficient of aqueous solution is positive, leads to decrease of fire extinguishing efficiency of foam. The value of minimum specific consumption increases from $1,7 \mathrm{~kg} / \mathrm{m} 2$ to $5,0 \mathrm{~kg} / \mathrm{m} 2$, and the value of optimum flow rate rises from $0,046 \mathrm{~kg} / \mathrm{m} 2 \mathrm{~s}$ to $0,066 \mathrm{~kg} / \mathrm{m} 2 \mathrm{~s}$.

Change of the value of parameters, defining fire extinguishing efficiency of foam, is connected with increase of the specific fracture rate of foam and increase of the thickness of minimal isolating foam layer. These values can be calculated on the basis of analysis of dependence of time and specific consumption on flow rate of foam-forming solution using formulas presented in works [10-13].

$$
\tau_{\mathrm{T}}=-\frac{\rho h_{0}}{\mathrm{~J}_{\mathrm{C}}}\left(1+\left(\frac{J}{J_{C}}\right)^{n}\right) \ln \left(1-\frac{J_{C}}{J}\right)
$$

$\rho$ - foam density, $\mathrm{kg} / \mathrm{m}^{3} ; \mathrm{h}_{0}$ - minimal thickness of isolating layer, $\mathrm{m} ; \mathrm{J}_{\mathrm{c}^{-}}$critical flow rate, $\mathrm{kg} / \mathrm{m}^{2} \mathrm{~s} ; \quad \mathrm{J}-$ current value of solution flow rate, $\mathrm{kg} / \mathrm{m}^{2}, \mathrm{n}-$ exponential quantity, characterizing the rate of rise of an average thickness of extinguishing layer.

For specific consumption $\mathrm{Q}: \mathrm{Q}=\mathrm{J}^{*} \tau_{\mathrm{T}}$,

$$
\mathrm{Q}=-\frac{\rho h_{0} J}{\mathrm{~J}_{\mathrm{C}}}\left(1+\left(\frac{J}{J_{C}}\right)^{n}\right) \ln \left(1-\frac{J_{C}}{J}\right)
$$

The results of calculation, using formulas (3) and (4), are selectively presented in fig. 1 and fig. 2.

According to results of calculation, values of minimal thickness of isolating layer - h0 and specific fracture rate of foam - Jc increase due to large concentration of electrolyte. Specific fracture rate of foam without additives of electrolyte is $0,028 \mathrm{~kg} / \mathrm{m}^{2} \mathrm{~s}$, and with additives of electrolyte $(2,0 \mathrm{~m} \%)$ is $0,031 \mathrm{~kg} / \mathrm{m}^{2} \mathrm{~s}$. Minimal thickness of foam isolating layer, formed from solutions with large concentration of salt increases from $4,1 \mathrm{~mm}$ to 5,1 $\mathrm{mm}$.

On the basis of experimental studies it is shown that addition of electrolyte - ammonium chloride - into aqueous solution of film-forming agent decrease interfacial tension on a border with heptane and increase surface tension on a border with air.

It is experimentally shown that dependence of specific consumption on flow rate of foaming agent passes through a minimum point that allow to define influence of concentration of electrolyte on a value of minimum specific consumption and optimum value of flow rate of foam during extinguishing of a hydrocarbon flame. The spreading structure in a foam solution - hydrocarbon system determines the value of fire extinguishing efficiency of foam which decreases together with lowering of spreading coefficient and interfacial tension values. 
The possibility of definition of the minimal thickness of foam isolating layer and specific fracture rate, using calculated ratios which connect the value of time and specific consumption of foaming agent with flow rate of solution, is shown.

\section{References}

1. D. White. Industrial Fire World, 21(1), 8-10 (2006)

2. K. D. Westwood, Industrial Fire World 21(1), 4-7 (2006)

3. A. F. Sharovarnikov, S. S. Voevoda, Proceedings of All-Russian meeting-seminar 1, 41-47 (1997)

4. A. D. Katayev, All-Russian meeting-seminar 1, 57-63 (1997)

5. A. F. Sharovarnikov, A. A. Yefimov, Fire Business 12, 91-96 (1991)

6. A. F. Sharovarnikov, N. K. Grashichev, S. S. Voyevoda, Collection of scientific papers 0000A, 32-35 (1991)

7. A. F. Sharovarnikov, V. P. Molchanov, Fire Business 1, 83-85 (1995)

8. A. Nakakuki, Haykan gidzyutsu kenkyu kekaysi 21(2), 73-77 (1981)

9. N. Nurimoto, Kasay 27(3), 11-19 (1977)

10. D. Korolchenko, A. Tusnin, S. Trushina, A. Korolchenko, International Journal of Applied Engineering Research 10(21), 42541-42548 (2015)

11. D. A. Korolchenko, A.F. Sharovarnikov, Advanced Materials Research 1070-1072, 1794-1798 (2015)

12. D. A. Korolchenko, A. F. Sharovarnikov, E. N. Degaev, Science Review 8, 114-120 (2015)

13. A. F. Sharovarnikov, D. A. Korolchenko, Applied Mechanics and Materials 475-476, 1344-1350 (2014) DOI: 10.4028/www.scientific.net/AMM.475-476.1344

14. A.D. Korolchenko, A.F. Sharovarnikov, A.V. Byakov, Advanced Materials Research 1073-1076, 2353-2357 (2015)

15. A.D. Korolchenko, A. F. Sharovarnikov, Fire and Explosion Safety 23(11), 84-88 (2014) DOI: 10.18322/PVB.2014.23.11.84-88

16. A.D. Korolchenko, A. F. Sharovarnikov, Fire and Explosion Safety 23(12), 59-68 (2014) DOI: 10.18322/PVB.2014.23.12.59-68 